\title{
Ảnh hưởng của văn hoá doanh nghiệp đến kết quả thực hiện công việc của người lao động tại Công ty cổ phẩn bất động sản Okamura Sanyo \\ The effects of organizational culture on performance of employees at Okamura Sanyo property corporation
}

\author{
Huỳnh Thị Thu Sương ${ }^{1 *}$, Lê Thị Thu Hường ${ }^{2}$ \\ ${ }^{1}$ Trường Đại học Tài chính - Marketing, Việt Nam \\ ${ }^{2}$ Công ty cổ phần bất động sản Okamura Sanyo, Việt Nam \\ *Tác giả liên hệ, Email: huynhthusuong@ufm.edu.vn
}

\section{THÔNG TIN}

DOI: $10.46223 / \mathrm{HCMCOUJS}$. econ.vi.17.1.1782.2022

Ngày nhận: 29/03/2021

Ngày nhận lại: 31/03/2021

Duyệt đăng: 06/05/2021

Tù khóa:

kết quả thực hiện công việc; sự gắn kết với doanh nghiệp; văn hoá doanh nghiệp

Keywords:

performance; organizational commitment; organizational culture

\section{TÓM TÁT}

Mục tiêu của nghiên cứu này nhằm xác định ảnh hưởng của văn hoá doanh nghiệp đến kết quả thực hiện công việc của người lao động trong Công ty Cổ Phần Bất Động Sản Okamura Sanyo. Dựa trên dữ liệu thu thập từ 246 nhân viên đang làm việc tại Công ty cổ Phần bất động sản Okamura Sanyo, nghiên cứu sử dụng các phương pháp phân tích số liệu bằng kỹ thuật thống kê mô tả, hệ số tin cậy Cronbach's alpha, phân tích nhân tố khám phá, phân tích nhân tố khẳng định. Kết quả nghiên cứu cho thấy văn hoá doanh nghiệp có ảnh hưởng rõ nét đến kết quả thực hiện công việc của người lao động bao gồm Sự tham gia của người lao động, Lương và khen thưởng, Chăm sóc khách hàng, Sự giao tiếp giữa các thành viên và Sự hợp tác giữa các thành viên. Kết quả nghiên cứu mang lại một số ý nghĩa thực tiễn giúp cho các nhà quản trị của Công ty cổ Phần bất động sản Okamura Sanyo nói riêng và các doanh nghiệp kinh doanh ngành dịch vụ quản lý và vận hành toà nhà, cảm nhận thấy sự quan trọng của các nhân tố văn hoá doanh nghiệp này đến kết quả thực hiện công việc của người lao động, từ đó có những điều chỉnh chiến lược xây dựng và phát triển văn hoá doanh nghiệp mang lại giá trị tích cực cho doanh nghiệp và là cơ sở cho các nghiên cứu tiếp theo.

\section{ABSTRACT}

The research is conducted to determine the effects of organizational culture on the performance of employees at Okamura Sanyo Property Corporation. In the quantitative research with sample size 246 who it's working in Okamura Sanyo Property Corporation. Using data analysis methods, including descriptive statistics methods, Cronbach's alpha test, Exploratory Factor Analysis (EFA), Confirmatory Factor Analysis (CFA) was used. The result of CFA indicates organizational culture in Okamura Sanyo Property Corporation is constituted of the elements: Employee participation, salary and reward, communication between members, customer care, collaboration of members. This study's findings show that organizational culture help managers of Okamura Sanyo Property Corporation in particular and real estate management services popular's corporation. Recognize the 
importance of organizational culture to the performance of employees. There are adjustments about strategy for building and developing an organizational culture that brings positive value for the company and the basis for further research.

\section{Giới thiệu}

Ngành dịch vụ tại Việt Nam đang đối mặt nhiều thách thức do suy thoái kinh tế dẫn đến thắt chặt chi tiêu và đòi hỏi khắt khe hơn về chất lượng dịch vụ. Để tồn tại, mở rộng và phát triển hoạt động của mình, các doanh nghiệp dịch vụ không chỉ phải duy trì tốt các mảng dịch vụ mà còn phải có những giá trị dịch vụ tăng thêm cung cấp đến khách hàng. Việc duy trì tốt các mảng dịch vụ và đem đến cho khách hàng những giá trị khác tốt hơn thì người lao động trong doanh nghiệp đó luôn đóng vai trò then chốt. Kết quả thực hiện của người lao động trong doanh nghiệp dịch vụ quyết định số phận doanh nghiệp đó. Gerson (as cited in Le, 2008) có đến $68 \%$ khách hàng mất lòng tin vào doanh nghiệp khi có ấn tượng xấu về cách ứng xử và phát ngôn của nhân viên tiếp xúc trực tiếp với khách hàng. Trong khi đó Barrect (as cited in Le, 2008) chỉ ra rằng $84 \%$ tác phong ứng xử của nhân viên với khách hàng không phù hợp với sự cam kết của doanh nghiệp. Điều này bắt nguồn từ sự không tin tưởng của nhân viên đối với tổ chức. Qua đó thấy được, một doanh nghiệp phát triển lớn mạnh hay không được xác định bằng kết quả làm việc của người lao động trong chính doanh nghiệp đó, các doanh nghiệp cần phải tập trung xây dựng hình ảnh và giá trị văn hóa của doanh nghiệp, nâng cao nhận thức của đội ngũ nhân viên để có được sự sự tin tưởng và ủng hộ của khách hàng. Nhằm mục đích tạo cho người lao động thực hiện tốt công việc nâng cao lợi thế cạnh tranh, tạo nên sự phát triển bền vững cho doanh nghiệp.

Chính vì vậy, văn hoá doanh nghiệp luôn là đề tài mà mọi doanh nghiệp quan tâm và thông qua xây dựng văn hoá doanh nghiệp để nâng cao kết quả thực hiện công việc của người lao động là vấn đề cốt yếu mà một doanh nghiệp dịch vụ cần phải làm. Lĩnh vực dịch vụ về quản lý các tòa nhà chung cư cũng là loại hình đang phát triển tại Viêt Nam, nghiên cứu này thực hiện tại Công ty Cổ Phần Bất Động Sản Okamura Sanyo trong hoàn cảnh cạnh tranh gay gắt giữa các doanh nghiệp cung cấp dịch vụ quản lý và vận hành toà nhà để tái khẳng định mục tiêu nghiên cứu đã đề cập ở trên.

\section{Tổng quan nghiên cứu}

\subsection{Một số khái niệm}

\subsubsection{Văn hoá doanh nghiệp (organizational culture)}

Văn hoá doanh nghiệp là một khuôn mẫu những quan niệm cơ bản được phát minh, được khám phá hoặc được phát triển bởi một nhóm người nhất định nào đó khi học được cách đối phó với những vấn đề thích nghi bên ngoài và hội nhập bên trong - vận hành đủ tốt để được coi như là có hiệu lực và do đó được sử dụng để giảng dạy cho nhân viên mới cách nhận thức, cách suy nghĩ và cách cảm nghĩ một cách đúng đắn khi đối phó với những vấn đề đó (Schein, 2004). Bao gồm: (i) Sự tham gia của người lao động (employee participation): Schein (1992) đã nghiên cứu và đưa ra kết luận, sự tham gia của người lao động được coi là yếu tố quan trọng để thiết lập mục tiêu tổ chức, tăng sự chấp thuận các mục tiêu của tổ chức. Sự tham gia có liên quan đến việc giao nhiệm vụ theo trách nhiệm của từng cá nhân, đóng góp thêm nhiều ý tưởng cho việc thiết lập các kế hoạch của tổ chức, xác định rõ trách nhiệm và nhiệm vụ của từng nhân viên. (ii) Lương và khen thưởng (salary and reward): Lương và khen thưởng: là khoản thu nhập mà người lao động được hưởng khi họ hoàn thành hoặc sẽ hoàn thành công việc theo chức năng. Khen thưởng là một trong những phương pháp khuyến khích vật chất đối với người lao động trong quá trình làm việc, qua đó nâng cao năng suất lao động, chất lượng sản phẩm. Để đạt được 
các mục tiêu, doanh nghiệp cần có công nghệ phù hợp, kế hoạch được thiết kế chiến lược, mô tả công việc toàn diện và các khóa đào tạo; bên cạnh đó cần có một hệ thống lương, khen thưởng đủ khả năng để khích lệ tinh thần làm việc và động viên người lao động (Luthans, 1998). (iii) Sự giao tiếp giữa các thành viên (communication between members): Sự giao tiếp giữa các thành viên: là tiến trình gởi, nhận và chia sẻ các ý tưởng, quan điểm, ý kiến và các sự kiện, là việc chuyển đổi thông tin và nhận thức từ người này sang người khác (Aydin \& Ceylan, 2009). Tổ chức ngày nay phải đối mặt với những vấn đề phức tạp và giải quyết vấn đề trong hệ thống phức tạp đòi hỏi sự tương tác tốt giữa các thành viên chứ không riêng một cá nhân cụ thể nào. Bằng cách giao tiếp tốt, kiến thức có thể được chia sẻ giữa các các thành viên trong doanh nghiệp và sự hiểu biết tốt hơn giữa các cá nhân với nhau, nhu cầu của họ và cách họ làm việc ở các bộ phận khác nhau của doanh nghiệp. (iv) Chăm sóc Khách hàng (customer care): là tất cả những gì mà một doanh nghiệp cần thiết phải làm để thỏa mãn nhu cầu và mong đợi của khách hàng; nói một cách khác, chăm sóc khách hàng là phục vụ khách hàng theo như cách họ mong muốn. Chăm sóc khách hàng có liên quan đến sự hài lòng của khách hàng (Aydin \& Ceylan, 2009). Nó là thước đo các sản phẩm, dịch vụ được cung cấp bởi một công ty đáp ứng hoặc vượt qua sự mong đợi của khách hàng. (v) Sự hợp tác giữa các thành viên (collaboration of members): Người lao động trong doanh nghiệp được mong đợi được sự hỗ trợ, hợp tác từ đồng nghiệp và cấp trên để vượt qua những thách thức trong công việc, sẵn sàng tìm ra hướng đi có ích nhất cho mọi thử thách trong công việc (Ginivicious \& Vaitkunaite, 2006). Doanh nghiệp có văn hoá đề cao sự hợp tác giữa các thành viên sẽ giúp nâng cao kết quả công việc, tiếp cận được nhiều nguồn lực hơn và phát triển các ý tưởng sáng tạo. Giúp người lao động có góc nhìn mới lạ và tích luỹ thêm kinh nghiệm từ người khác. Ginivicious và Vaitkunaite (2006) chỉ ra rằng sự hợp tác có tác động mạnh đến kết quả công việc của người lao động.

\subsubsection{Gắn kết với doanh nghiệp (organizational commitment)}

Theo Meyer và Allen (1991) cho rằng gắn kết với doanh nghiệp là ở lại với doanh nghiệp, tham gia công việc thường xuyên, nỗ lực làm việc mỗi ngày, bảo vệ tài sản của doanh nghiệp và tin vào mục tiêu của doanh nghiệp. Với Cohen, Manion, và Morrison (2007), sự gắn kết với doanh nghiệp là lòng trung thành của nhân viên với doanh nghiệp, sẵn sàng nỗ lực hết mình vì mục tiêu, giá trị của tổ chức và mong muốn duy trì là thành viên của tổ chức. Vậy gắn kết với doanh nghiệp là sự sẵn sàng làm việc tích cực vì doanh nghiệp, cảm thấy tự hào là một thành viên của doanh nghiệp và có sự gắn bó chặt chẽ với doanh nghiệp.

2.1.3. Kết quả thưc hiện công việc của ngườ lao động (performance of employees) là khả năng nhân viên đạt được mục tiêu hoặc của cá nhân hoặc của tổ chức bằng cách sử dụng các nguồn lực một cách hiệu quả (Shahzad, Iqbal, \& Gulzar, 2013). Vậy, kết quả làm việc là đầu ra hoặc là kết quả của hành vi thực hiện công việc. Hành vi này được thực hiện bởi từng cá nhân riêng lẻ, xuất phát từ việc được giao trách nhiệm thực hiện từ tổ chức. Kết quả công việc đề cập đến kết quả đầu ra, kết quả thu được từ quá trình và được cho phép so sánh, đánh giá tương đối với mục tiêu, kết quả trong quá khứ.

\subsubsection{Mối liên hệ giữa Văn hoá doanh nghiệp và Sự gắn kết}

Nghiên cứu của Khan, Asghar, và Zaheew (2014) khám phá rằng các công ty có văn hoá trong công việc sẽ có sự lượng nhân sự gắn kết hơn. Công ty nào có văn hoá tôn trọng, khuyến khích người lao động sáng tạo, đóng góp ý kiến và tham gia nhóm làm việc chung thì xu hướng người lao động muốn gắn kết hơn với công ty đó. Văn hoá doanh nghiệp tác động trực tiếp và gián tiếp đến sự gắn bó với doanh nghiệp thông qua các chính sách tổ chức như chính sách lương, thưởng, tôn trọng quyền người lao động (Manetje \& Martins, 2009). Sự ảnh hưởng này xuất hiện khi các thành viên của doanh nghiệp tìm thấy giá trị niềm tin của doanh nghiệp tương đồng với giá trị niềm tin của cá nhân. Vì vậy mà văn hoá doanh nghiệp tác động đến sự gắn kết của người lao động với doanh nghiệp thông qua các chính sách tổ chức như chính sách lương, 
thưởng, tôn trọng quyền người lao động.

\subsubsection{Mối liên hệ giũa Sụ gắn kết và Kết quả thực hiện công việc}

Nehmeh (2009) cho rằng sự gắn kết có một giá trị rất to lớn trong doanh nghiệp. Trong nghiên cứu của mình, tác giả nhấn mạnh rằng sự cam kết có một tác động mạnh mẽ đến hiệu suất và thành công của một tổ chức. Bởi lẽ các nhân viên có sự cam kết cao sẽ xác định được các mục tiêu và giá trị của doanh nghiệp, họ có một mong muốn mạnh mẽ được gắn bó với doanh nghiệp và sẵn sàng hoàn thành nhiệm vụ vượt yêu cầu của cấp trên. Người lao động gắn bó với tổ chức theo các tiêu chí này sẽ trở thành tài sản, thế mạnh phục vụ cho lợi thế cạnh tranh bền vững của tổ chức (Bhatnagar, 2007). Imamoglu, Ince, Turkcan, và Atakay (2019) cho rằng sự cam kết gắn bó với doanh nghiệp thúc đẩy cá nhân người lao động hành động vì mục tiêu của doanh nghiệp, làm giảm hành vi có hại cho doanh nghiệp như đi trễ, vắng mặt. Một người lao động muốn gắn kết với doanh nghiệp họ sẽ nỗ lực hơn để đạt mục tiêu, do vậy mà kết quả thực hiện công việc cũng tốt hơn, dịch vụ cung cấp cho khách hàng cũng vì vậy mà tốt hơn. Các doanh nghiệp có đội ngũ nhân viên ổn định và chuyên nghiệp sẽ cho kết quả công việc tốt hơn giúp doanh nghiệp thu hút được nhiều nhà đầu tư, giá trị doanh nghiệp sẽ ngày càng tăng thêm. Ngoài những yếu tố kể trên Bozlagan, Dogan, và Daoudov (2010) đã chỉ ra những vai trò quan trọng của sự gắn kết như: giúp nâng cao sự hài lòng của nhân viên trong doanh nghiệp, cải thiện bầu không khí trong doanh nghiệp theo chiều hướng tích cực, làm gia tăng thu nhập của người lao động; giữ chân người lao động ở lại với doanh nghiệp phát huy tinh thần đồng đội trong doanh nghiệp, làm gia tăng hiệu qủa làm việc của người lao động, giúp cải thiện lòng tin của người lao động đối với doanh nghiệp, giúp doanh nghiệp linh hoạt để ứng phó với những tình huống xảy ra, góp phần vào sự phát triển của doanh nghiệp. Vì vậy, trong một doanh nghiệp, đội ngũ nhân viên có trình độ chuyên môn tốt, muốn đóng góp và gắn bó lâu dài với doanh nghiệp có thể giúp doanh nghiệp tạo ra nhiều sản phẩm, dịch vụ mới có chất lượng tốt, giá cả cạnh tranh.

\subsection{Mô hình nghiên cúu đề xuất}

Dựa trên nền cơ sở lý thuyết và tổng quan nghiên cứu, tác giả kế thừa và điều chỉnh có chọn lọc nhằm đề xuất cho mô hình các nhân tố văn hoá doanh nghiệp như Hình 1 gồm : (1) Sự tham gia của người lao động; (2) Lương và khen thưởng; (3) Sự giao tiếp giữa các thành viên; (4) Chăm sóc khách hàng; (5) Sự hợp tác giữa tác giữa các thành viên, tác động đến sự gắn kết của người lao động làm ảnh hưởng kết quả thực hiện công việc của người lao động theo nghiên cứu của Shahzad và cộng sự (2013); Aydin và Ceylan (2009); Imamoglu và cộng sự (2019); Rodríguez, Afonso, và Rosa (2020); S. S. Kim, Im, và Hwang (2009); Bozlagan và cộng sự (2010).

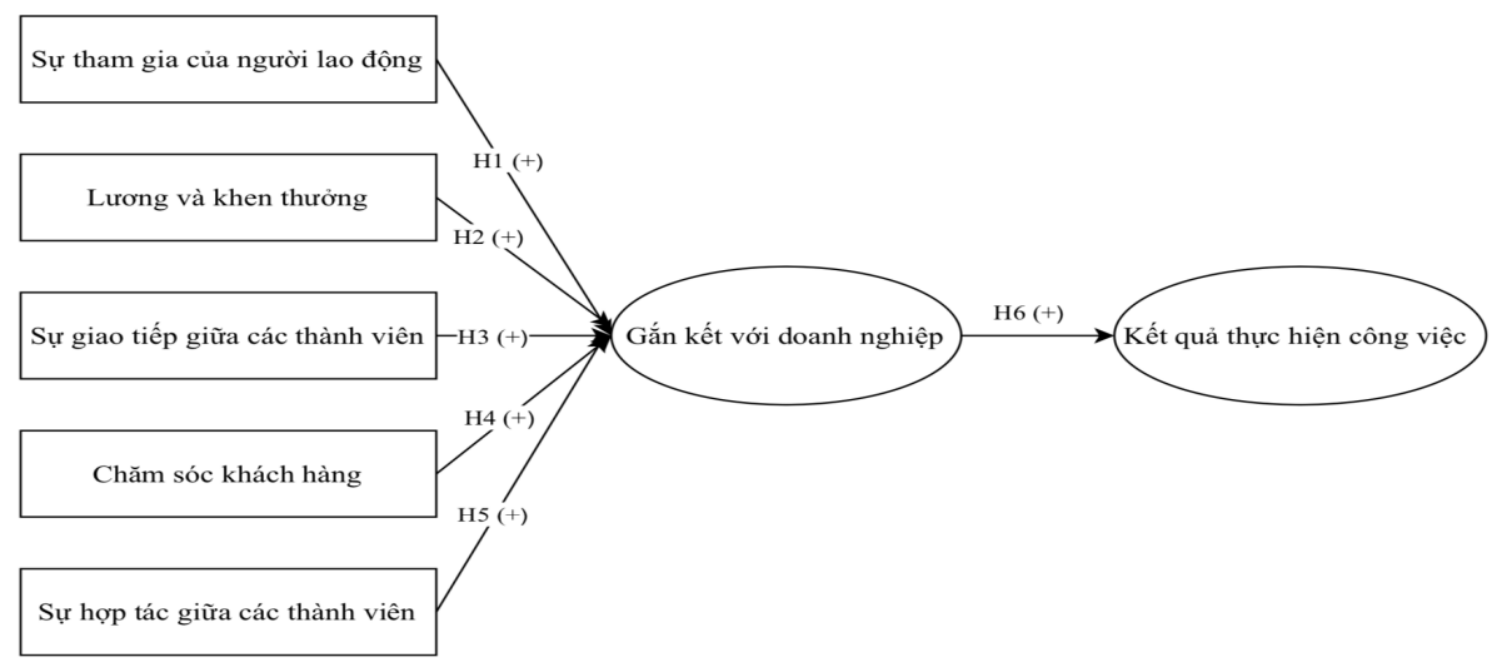

Hình 1. Mô hình nghiên cứu nhóm tác giả đề xuất (2021) 


\section{Phương pháp nghiên cứu}

Nghiên cứu sẽ được thực hiện theo hai bước chính là nghiên cứu sơ bộ và nghiên cứu chính thức. Mỗi giai đoạn được tiến hành với kỹ thuật tương ứng: (1) Nghiên cứu sơ bộ được thực hiện thông qua hai phương pháp là định tính: thảo luận nhóm, xây dựng thang đo và định lượng là: đánh giá sơ bộ và hiệu chỉnh thang đo; và định lượng là: đánh giá sơ bộ và hiệu chỉnh thang đo; (2) Nghiên cứu định lượng chính thức là kiểm định thang đo và mô hình các giả thuyết. Trên cơ sở nghiên cứu sơ bộ định tính được thực hiện thông qua thảo luận nhóm với 11 người làm việc tại doanh nghiệp và phương pháp nghiên cứu định lượng - thông qua phương pháp phỏng vấn trực tiếp nhân viên bằng bảng câu hỏi chính thức với 246 bảng trả lời hợp lệ. Thang đo các yếu tố văn hoá doanh nghiệp ảnh hưởng đến kết quả thực hiện công việc của người lao động làm việc tại OSP thông qua sự gắn kết của người lao động với doanh nghiệp gồm có: 05 biến độc lập (independent variables): (1) Sự tham gia của người lao động; (2) Lương và khen thưởng; (3) Sự giao tiếp giữa các thành viên; (4) Chăm sóc khách hàng và (5) Sự hợp tác giữa các thành viên. Biến trung gian (mediating variables): Gắn kết với doanh nghiệp. Biến phụ thuộc (dependent variables) là Kêt quả thực hiện công việc của người lao động.

\section{Kết quả nghiên cứu}

\section{Bảng 1}

\begin{tabular}{|c|c|c|c|}
\hline & Chỉ tiêu & Số lượng (khảo sát) & Tỷ lệ (\%) \\
\hline \multirow{2}{*}{ Giới tính } & Nam & 54 & 22.0 \\
\hline & Nữ & 192 & 78.0 \\
\hline \multirow{3}{*}{ Vị trí công việc } & Nhân viên dự án & 142 & 57.7 \\
\hline & Nhân viên hành chính văn phòng & 44 & 17.9 \\
\hline & Nhân viên marketing và kế toán & 38 & 15.4 \\
\hline \multirow{4}{*}{ Thu nhập } & Dưới 10 triệu & 73 & 29.7 \\
\hline & Từ 10 đến dưới 15 triệu & 133 & 54.1 \\
\hline & Từ 15 - 20 triệu & 24 & 9.8 \\
\hline & Trên 20 triệu & 16 & 6.5 \\
\hline Tổng cộng & & 246 & 100.0 \\
\hline
\end{tabular}

Đặc điểm mẫu khảo sát

Nguồn: Tác giả tổng hợp - Phòng Hành chính Nhân sự Công ty cổ phần bất động sản Okamura Sanyo (2021)

Người lao động được khảo sát chủ yếu là nam giới với 192 khảo sát, chiếm tỷ trọng là $78.0 \%$. Với độ tuổi chủ yếu là dưới 30 tuổi (139 khảo sát, với 59.5\%), các đối tượng này tập trung chủ yếu là nhân viên kinh doanh (142 khảo sát, với $57.7 \%)$, với thu nhập từ 10 - 15 triệu/tháng (133 khảo sát, chiếm 54.1\%). 


\section{Bảng 2}

Kết quả kiểm định thang đo bằng Cronbach's Alpha

\section{Yếu tố}

Sự tham gia công việc của người lao động

Lương và khen thưởng

Sự giao tiếp của các thành viên

Chăm sóc khách hàng

Sự hợp tác giữa các thành viên

Gắn kết với doanh nghiệp

Kết quả thực hiện công việc

\begin{tabular}{cc} 
Số biến quan sát \\
\hline Truớc
\end{tabular}

4

5

$4 \quad 4$

4

4

5

4
Hệ số

Cronbach's Alpha

0.897

0.824

0.891

0.909

0.911

0.895

0.816

Nguồn: Kết quả xử lý dữ liệu của nhóm tác giả (2021)

Kết quả kiểm định Cronbach’ Alpha (Bảng 1) cho thấy thang đo đạt độ tin cậy cao vì hệ số tổng biến của tất cả các thang đo của yếu tố độc lập đều lớn hơn 0.6. Bên cạnh đó hệ số Cronbach's Alpha tương quan biến tổng nhỏ nhất của các thang đo thuộc yếu tố độc lập đều có giá trị $>0.4$.

Phân tích khám phá nhân tố EFA có: Giá trị $\mathrm{KMO}=0.898>0.6$ nghĩa là tương quan giữa các biến quan sát đủ lớn để tiến hành phân tích nhân tố. Kiểm định Bartlett's có mức ý nghĩa sig = $0.000<5 \%$, chứng tỏ các yếu tố được rút trích là phù hợp, nên các biến quan sát có tương quan với nhau. Giá trị phương sai trích $=69.645 \%>50 \%$ chứng tỏ 31 biến rút trích được sáu yếu tố ảnh hưởng đến kết quả làm việc của người lao động là phù hợp với dữ liệu. Phương sai trích đạt $69.645 \%$ thể hiện rằng năm nhân tố rút ra giải thích được $69.645 \%$ biến thiên của dữ liệu. Có năm yếu tố được rút trích tại điểm trích $=1.9>1$ nên năm yếu tố đại diện cho 26 biến quan sát.

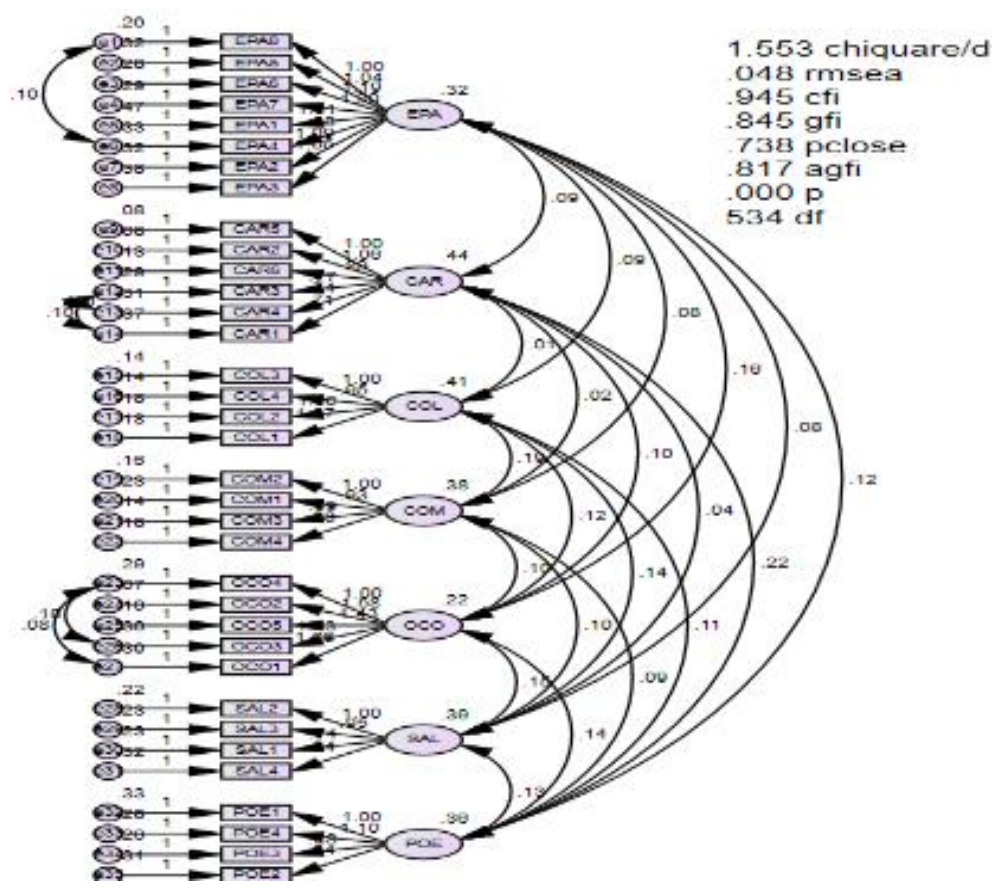

Hình 2. Kết quả CFA của toàn bộ mô hình nghiên cứu đã chuẩn hoá Nguồn: Kết quả xử lý dữ liệu của nhóm tác giả (2021) 
Kết quả CFA (Hình 2) cho thấy mô hình có 534 bậc tự do, giá trị kiểm định chi-square/df $=1.553<3$ (Đủ điều kiện) với $\mathrm{p}$-value $=0.000$, và các chỉ số chỉ ra mô hình phù hợp với dữ $(\mathrm{CFI}=0.945 ; \mathrm{GFI}=0.845$, AGFI $=0.817$ và $\mathrm{RMSEA}=0.048 ;$ Pclose $=0.738)$. Vì vậy, các thang đo sự gắn kết với tổ chứcnghiệp tác động đến kết quả làm việc của người lao động đều đạt giá trị phân biệt.

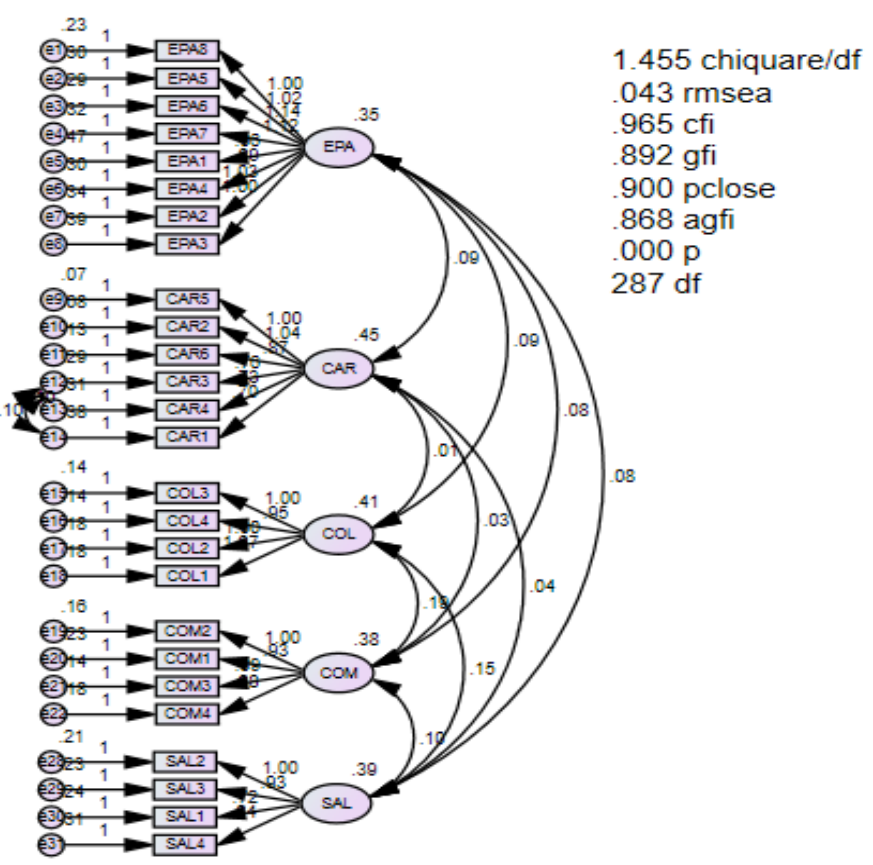

Hình 3. Kết quả CFA thang đo các yếu tố ảnh hưởng đến kết quả làm việc đã chuẩn hóa Nguồn: Kết quả xử lý dữ liệu của nhóm tác giả (2021)

Kết quả CFA (Hình 3) cho thấy mô hình có 287 bậc tự do, giá trị kiểm định chi-square/df $=1.455<3$ với $\mathrm{p}$-value $=0.000$ và các chỉ số chỉ ra mô hình phù hợp với dữ $(\mathrm{CFI}=0.965$ và RMSEA $=0.043$; Pclose $=0.900 ; \mathrm{GFI}=0.892$, AGFI $=0.868$ ). Vì vậy, thang đo các yếu tố ảnh hưởng đến kết quả làm việc của người lao động đều đạt giá trị phân biệt. Như vậy các biến quan sát thuộc các thành phần sự gắn kết với tổ chức ảnh hưởng đến kết quả làm việc của người lao động đạt được giá trị hội tụ.

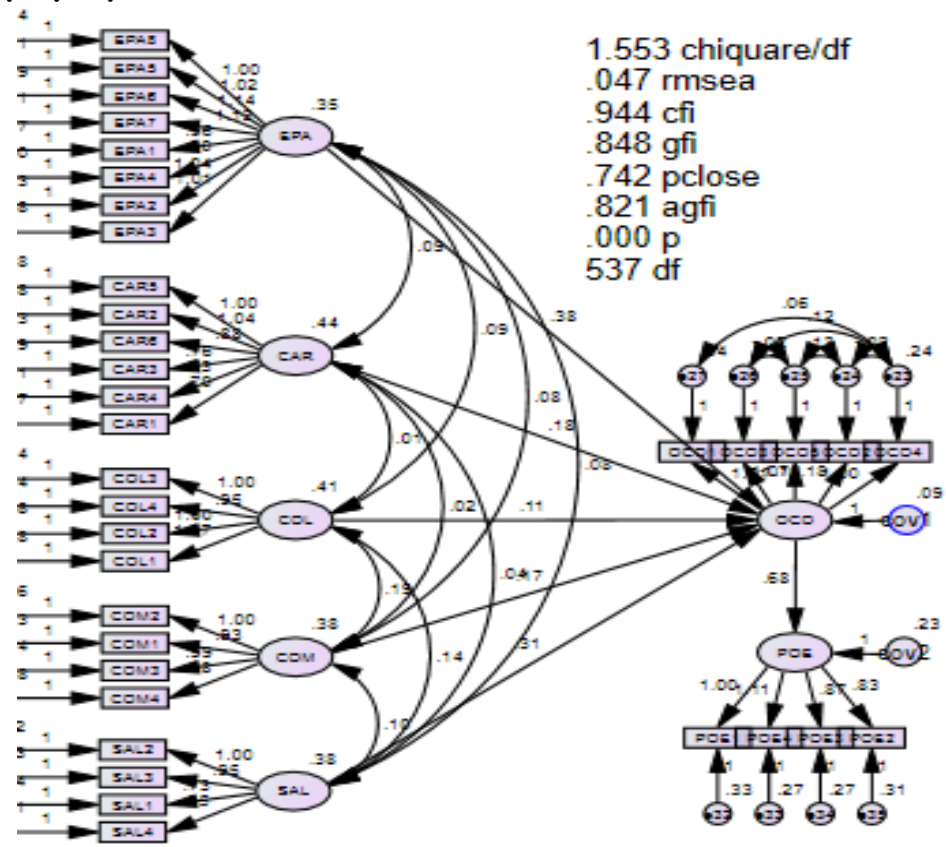

Hình 4. Mô hình kiểm định các giả thuyết nghiên cứu

Nguồn: Kết quả xử lý dữ liệu từ điều tra của nhóm tác giả (2021) 
Kết quả chạy SEM (hình 4) của toàn bộ mô hình này, tác giả nhận thấy độ phù hợp của mô hình kiểm định là khá cao, thỏa mãn các điều kiện đó là $\mathrm{CMIN}=1.553<3$; RMSEA $=0.046<$ $0.05 ; \mathrm{CFI}=0.944>0.9 ; \mathrm{GFI}=0.848>0.8$, Pclose $=0.742>0.05$. Bậc tự do $(\mathrm{df})=537$ và p-value $=0.000<0.05$. Sau cùng, từ kết quả kiểm định giả thuyết nghiên cứu có $06 / 06$ giả thuyết được ủng hộ. Cụ thể, giả thuyết các yếu tố (1) Sự tham gia vào công việc (EPA), (2) Lương, thưởng, (3) Chăm sóc khách hàng $(\mathrm{CAR}),(4)$ Sự giao tiếp giữa các thành viên $(\mathrm{COM}),(5)$ Sự hợp tác giữa các thành viên $(\mathrm{COL})$ có tác động cùng chiều đến biến phuộc là sự gắn kết với tổ chức $(\mathrm{OCO})$. Giả thuyết H6, yếu tố sự gắn kết với tổ chức $(\mathrm{OCO})$ tác động cùng chiều đến kết quả thực hiện công việc của người lao động (POE). Kết quả kiểm định cho thấy mô hình phù hợp, không có sự vi phạm các giả định kiểm định, kết quả kiểm định các giả thuyết đều được chấp nhận.

Kết quả nghiên cứu phù hợp với các nghiên cứu trước, cụ thể Schein (1992) đã nghiên cứu và đưa ra kết luận, sự tham gia của người lao động được coi là yếu tố quan trọng để thiết lập mục tiêu tổ chức, tăng sự chấp thuận các mục tiêu của tổ chức. Sự tham gia có liên quan đến việc giao nhiệm vụ theo trách nhiệm của từng cá nhân, đóng góp thêm nhiều ý tưởng cho việc thiết lập các kế hoạch của tổ chức, xác định rõ trách nhiệm và nhiệm vụ của từng nhân viên. Bên cạnh đó, cũng giúp cho người lao động đạt được kết quả công việc tốt hơn bằng cách tạo cho họ cảm giác như đang kiểm soát công việc của mình. Điều này cho phép người lao động tham gia vào các hoạt động của tổ chức để giải quyết sự xung đột và sự mơ hồ trong công việc. Xung đột xảy ra khi người lao động có sự mơ hồ, khi không có đủ thông tin tương xứng để hoàn thành công việc. Khi doanh nghiệp cho phép người lao động tham gia vào các quyết định của tổ chức thì sẽ làm cho người lao động có thái độ tích cực, sáng tạo cũng như có trách nhiệm hơn với công việc, từ đó làm cho năng suất làm việc cao hơn. Theo $\mathrm{S}$. Kim và Lee (2006), có sự tham gia quản lý kết hợp giám sát, giao tiếp có hiệu quả có thể làm tăng kết quả đối với công việc. Johnson và McIntye (1998) tìm thấy rằng, văn hóa doanh nghiệp liên quan mạnh mẽ đến kết quả đối với công việc của người lao động thông qua việc trao quyền, sự tham gia của người lao động và sự công nhận từ cấp trên. Shahzad và cộng sự (2013) đã kết luận, sự tham gia của người lao động là một trong năm yếu tố có ảnh hưởng đến kết quả công việc của người lao động. Bên cạnh đó, nghiên cứu của Ginivicious và Vaitkunaite (2006) cũng đưa ra kết luận sự tham gia của người lao động có ảnh hưởng đến kết quả công việc.

\section{Một số hàm ý quản trị}

Dựa vào kết quả nghiên cứu là có sự ảnh hưởng tích cực của văn hoá doanh nghiệp đến kết quả thực hiện công việc của người lao động tại Công ty Cổ phần bất động sản Okamura Sanyo, một số hàm ý quản trị được đề xuất nhằm nâng cao kết quả thực hiện công việc của người lao động tại Công ty Cổ phần bất động sản Okamura Sanyo. Bên cạnh đó, công ty cần duy trì chủ trương khuyến khích sự tham gia của người lao động trong công việc; trong hoạt động xã hội và văn hoá tôn trọng ý kiến người lao động. Đồng thời tăng cường khơi dậy động lực bên trong của người lao động là ý thức tự chủ - tự quản thông qua việc để họ được tham gia những công việc quan trọng, tham gia vào nhóm làm việc có cấp trên. Hơn thế nữa, việc xây dựng một chính sách lương với tiêu chí rõ ràng minh bạch, các nội dung được chuẩn hóa theo thang điểm số để thuận tiện trong việc tính toán và tạo sự công bằng cho toàn thể người lao động. Ngoài việc hoàn thành các khoản phúc lợi xã hội như bảo hiểm xã hội, bảo hiểm y tế thì nên mua các gói bảo hiểm sức khỏe tự nguyện cho người lao động như bảo hiểm 24/24 để đem lại sự an tâm và niềm tin của người lao động. Chú trọng nâng cấp hệ thống chăm sóc khách hàng từ nhân viên chăm sóc khách hàng đến tổng đài hỗ trợ. Đặc biệt có nhân viên chăm sóc khách hàng tại các dự án để chủ động hỏi thăm khách hàng, lắng nghe và đáp ứng kịp thời những yêu cầu từ khách hàng. Một cách thức cũng mang lại hiệu quả quản lý là công ty phải ý thức trong việc tạo ra những buổi họp mặt kết nối nhân sự thường xuyên như đi xem phim, du lịch. Mở các lớp học rèn luyện thể lực cũng như trí óc như học yoga và ngoại ngữ ngoài giờ hay chương những chương trình thiện nguyện - giúp đỡ hoàn cảnh khó khăn. 


\section{Tài liệu tham khảo}

Aydin, B., \& Ceylan, A. (2009). The role of organizational culture on effectiveness. Ekonomika A. Management, 12(3), 33-49.

Bhatnagar, J. (2007). Talent management strategy of employee engagement in Indian ITES employees: Key to retention. Employee Relations, 29(6), 640-663.

Bozlagan, R., Dogan, M., \& Daoudov, M. (2010). Organizational commitment and case study on the union of municipalities of marmara. Regional and Sectoral Economic Studies, EuroAmerican Association of Economic Development, 10(2), 10-29.

Cohen, L., Manion, L., \& Morrison, K. (2007). Research methods in education (6th ed.). London, UK: Routledge/Taylor \& Francis Group.

Rodríguez, F. J. G., Afonso, D. D., \& Rosa, M. G. D. L. (2020). Hospitality diversity management and job satisfaction: The mediating role of organizational commitment across individual differences. International Journal of Hospitality Management, 91, 49-61.

Ginivicious, R., \& Vaitkunaite, V. (2006). Analysis of organizational culture dimensions impacting performance. Journal of Business Economics and Management, 7(4), 201-211.

Imamoglu, S. Z., Ince, H., Turkcan, H., \& Atakay, B. (2019). The effect of organizational justice and organizational commitment on knowledge sharing and firm performance. Procedia Computer Science, 158(2019), 899-906.

Johnson, J. J., \& McIntye, C. L. (1998). Organizational culture and climate correlates of job satisfaction. Educational and Psychological Measurement, 47(4), 1031-1036.

Khan, S., Asghar, M., \& Zaheew, A. (2014). Imfluence of leadership on employee job satisfaction and firm financial performance: A study of banking sector in Islamabab, Pakistan. Actual Problem of Economic, 5(155), 53-63.

Kim, S. S., Im, J., \& Hwang, J. (2009). The effects of mentoring on role stress, job attitude, and turnover intention in the COLel industry. International Journal of Hospitality Management, 48, 68-82.

Kim, S., \& Lee, H. (2006). The impact of organizational context and information technology on employee knowledge-sharing capabilities. Public Administration Review, 66(3), 370-385.

Le, C. C. (2008). Thuơng hiệu và văn hóa [Brand and culture]. Retrieved February 13, 2020, from Thời báo Kinh tế Sài Gòn website: https://www.thesaigontimes.vn/8163/Thuonghieu-va-van-hoa.html

Luthans, F. (1998). Organisational behaviour (8th ed.). Boston, MA: Irwin McGraw- Hill.

Manetje, O., \& Martins, N. (2009). The relationship between organisational culture and organisational commitment. Southern African Business Review, 13(1), 87-111.

Martins, H., \& Proenca, T. (2012). Minnesota satisfaction questionnaire - Psychometric properties and validation in a population of portuguese hospital workers. Retrieved February 16, 2020, from University of Porto website: http://wps.fep.up.pt/wps/wp471.pdf

Meyer, J. P., \& Allen, N. J. (1991). A three-component conceptualization of organizational Commitment. Human Resource Management Review, 1(1), 61-89.

Murphy, K., \& Cleveland, J. (1991). Performance appraisal: An organizational perspective. Boston, MA: Allyn \& Bacon. 
Nehmeh, R. (2009). What is organizational commitment, why should managers want it in their workforce and is there any cost effectives way to secure it? (SMC Working paper, No. 05/2009). Zug, Switzerland: Swiss Management Center. Retrieved December 10, 2020, from https://www.smcuniversity.com/working_papers/Ranya_Nehmeh_-_What_is_ Organizational_commitment,_why_should_managers_want_it_in_their_workforce_and_is _there_any_cost_effective_way_to_secure_it.pdf

Schein, E. H. (1992). Organizational culture and leadership (2nd ed.). San Francisco, CA: Jossey-Bass.

Schein, E. H. (2004). Organizational culture and leadership. (3rd ed.). San Francisco, CA: Jossey-Bass.

Shahzad, F. (2014). Impact of organizational culture on employees' job performance: An empirical study of software houses in Pakistan. International Journal of Commerce and Management, 24(3), 219-227.

Shahzad, F., Iqbal, Z., \& Gulzar, M. (2013). Impact of organizational culture on employees job performance: An empirical study of software houses in Pakistan. Journal of Business Studies Quarterly, 5(2), 56-64. 